\title{
Management of raised intracranial pressure
}

\author{
J D Pickard, M Czosnyka
}

\begin{abstract}
Epidemiology
Raised intracranial pressure (ICP) is the final common pathway for many intracranial problems (table 1) and has a profound influence on outcome. For example, of the 3-500 000 patients with head injury seen in Accident and Emergency Departments in the United Kingdom per annum, $20 \%$ are admitted of whom $10 \%$ are in coma (2\% of all attenders). Over $50 \%$ of these have an intracranial pressure greater than $20 \mathrm{~mm} \mathrm{Hg.}{ }^{12}$ A total of $80 \%$ of patients with fatal head injuries $(4 \%$ of all patients with head injuries admitted) show evidence of a significant increase in intracranial pressure at necropsy. Some $35 \%$ of severe head injuries die and $18 \%$ are left severely disabled at enormous financial and emotional cost to the family and community. Similarly, 20 per 100000 per year are admitted with intracerebral haematoma and 10-12 per 100000 per annum with subarachnoid haemorrhage. The average regional neurosurgical unit serving a population of two million will manage 200 patients per annum with brain tumours, some 15 patients with chronic subdural haematoma, and a similar number of patients with a cerebral abscess and 50 patients with hydrocephalus. ${ }^{3}$ In comatose children the incidence of raised ICP was $53 \%$ of those with head injuries, $23 \%$ with anoxicischaemia damage, $66 \%$ with meningitis, $57 \%$ with encephalitis, $100 \%$ with mass lesions and $80 \%$ with hydrocephalus. ${ }^{4}$ There is a considerable risk in all such patients of secondary brain damage with long term severe disability if raised intracranial pressure is not recognised and managed appropriately.
\end{abstract}

\section{Pathophysiology}

Resting ICP represents that equilibrium pressure at which CSF production and absorption are in balance and is associated with an equivalent equilibrium volume of CSF. CSF is actively secreted by the choroid plexus at about $0.35 \mathrm{ml} /$ minute and production remains constant provided cerebral perfusion pressure is adequate. CSF absorption is a passive process through the arachnoid granulations and increases with rising CSF pressure:

\section{Neurosurgical Unit}

(Box 167), Level 4, A

Block, Addenbrooke's

Hospital, Cambridge, CB2 2QQ, UK

J D Pickard

M Czosnyka

\section{CSF drainage $=$ CSF pressure - sagittal sinus pressure outflow resistance}

(Reference 22).
The 'four-lump' concept describes most simply the causes of raised ICP: the mass, CSF accumulation, vascular congestion and cerebral oedema (table 2)..$^{5-7}$ The description of a patient with raised ICP as having cerebral congestion, vasogenic oedema etc, can only be a working approximation, albeit useful, until our rather crude methods of assessment are refined. In adults, the normal ICP under resting conditions is between 0-10 $\mathrm{mmHg}$ with $15 \mathrm{mmHg}$ being the upper limit of normal. Active treatment is normally instituted if ICP exceeds $25 \mathrm{mmHg}$ for more than 5 minutes although a treatment threshold of $15-20 \mathrm{mmHg}$ has been suggested to improve outcome. ${ }^{8}$ In the very young, the upper limit of normal ICP is up to $5 \mathrm{mmHg}{ }^{49}$ Small increases in mass may be compensated for by reduction in CSF volume and cerebral blood volume but, once such mechanisms are exhausted, ICP rises with increasing pulse pressure and the appearance of spontaneous waves (plateau and B waves). ${ }^{10}$ There is an exponential relationship between increase in volume of an intracranial mass and the increase in intracranial pressure at least within the clinically significant range.

Cerebral perfusion pressure is commonly defined as: CPP = mean arterial blood pressure-mean ICP; mean ICP closely approximates to mean cerebral venous pressure. As cerebral perfusion pressure (CPP) falls with increasing ICP, ICP pulse pressure increases (fig 1). ${ }^{112}$ Firstly, the brain is less compliant or stiffer and a given pulsatile cerebral blood volume load provokes a bigger pressure response. Secondly, the pulsatile component of cerebral blood flow increases with decreasing CPP. Cerebral arteriolar dilatation to maintain cerebral perfusion ('autoregulation') may be involved. The lower limit of CPP which will permit autoregulation, when ICP is raised, is about $40 \mathrm{mmHg}$. However, there is a paradox: the level of CPP below which outcome after severe head injury and associated parameters deteriorate is of the order of 60-65 mmHg (MAP < $80 \mathrm{mmHg}$; ICP > 20 $\mathrm{mmHg}$ ). Conventionally any elevation of ICP requires treatment if CPP is below $60 \mathrm{mmHg}$ in adults for over 5 minutes. This paradox may partly reflect the 'split brain' problem: autoregulation of $\mathrm{CBF}$ to changes in CPP and response to changes in arterial carbon dioxide tension $\left(\mathrm{PaCO}_{2}\right)$ may be impaired focally, leaving intact reactivity in other areas 


\section{Table 1 Some common causes of raised ICP}

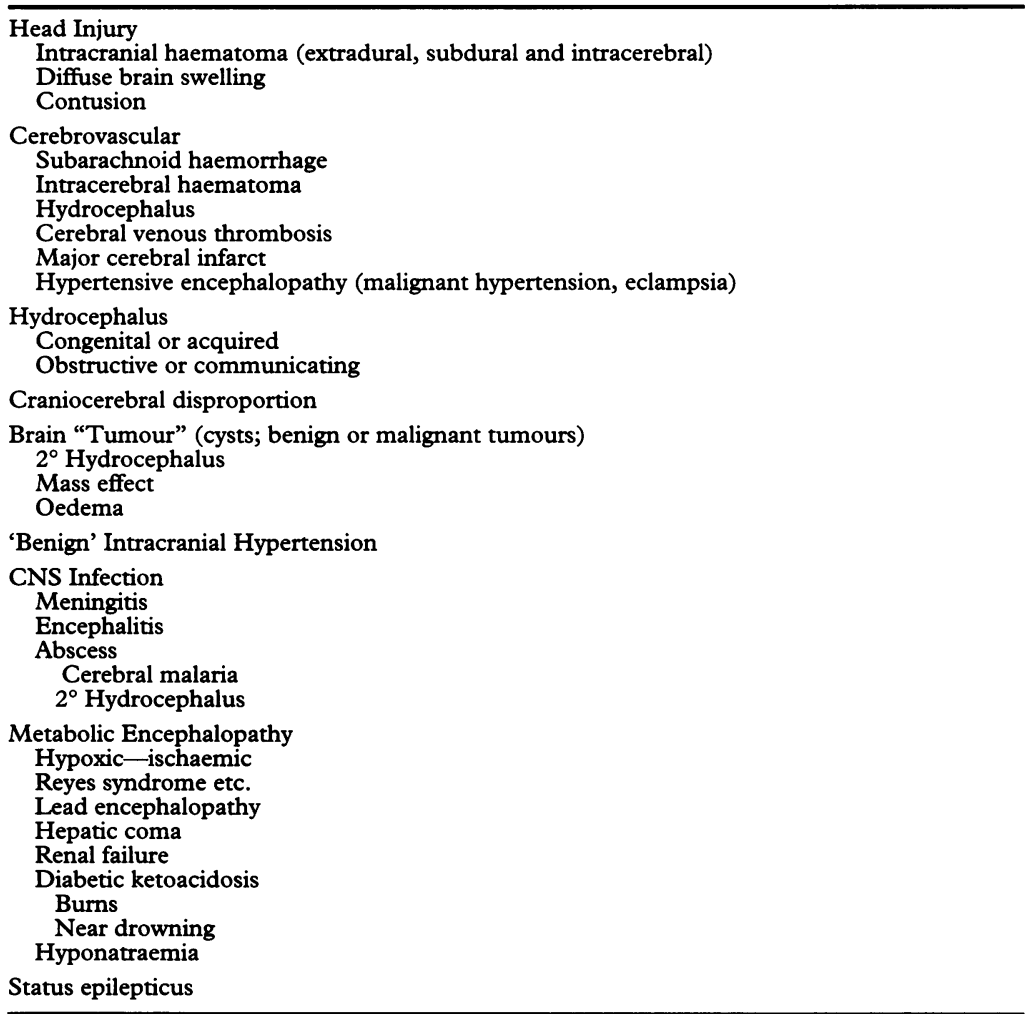

(Adapted from references 4, 5, 6, 7)

of the brain. If vasospasm is present, an even higher perfusion pressure may be required to provide adequate levels of cerebral blood flow. One interesting phenomenon revealed by transcranial Doppler (which reflects flow in large vessels) and laser Doppler (which reflects tissue perfusion) is the change in flow and perfusion during the cardiac cycle: diastolic perfusion pressure may be below the normal limit of autoregulation whilst systolic is above (vide infra).

Total cerebral blood flow may be increased or decreased in areas with absent reactivity. Hyperaemia is non-nutritional 'luxury perfusion' where CBF is in excess of the brain's metabolic requirements ${ }^{13}$ and accompanied by early filling veins on angiography and 'red veins' at operation. Cerebral vasodilators such as carbon dioxide will dilate 'normal' arterioles, increase ICP and may run the risk of reducing flow to damaged areas of brain (intracerebral 'steal'). Inverse 'steal' is one

Table 2 Mechanisms of raised ICP

\begin{tabular}{ll}
\hline A Mass Lesions & Haematoma, abscess, tumour. \\
B CSF Accumulation & Hydrocephalus (obstructive and communicating) and \\
including contralateral ventricular dilatation from & supratentorial brain shift. \\
C Cerebral Oedema & Increase in brain volume as a result of increased water \\
& content. \\
1 Vasogenic-vessel damage (tumour, abscess, \\
contusion) \\
2 Cytotoxic-cell membrane pump failure \\
(hypoxaemia, ischaemia, toxins; myelinoclastic). \\
3 Hydrostatic-high vascular transmural pressure (loss \\
of autoregulation; post intracranial decompression). \\
4 Hypo-osmolar-hyponatraemia \\
5 Interstitial-high CSF pressure (hydrocephalus) \\
Increased cerebral blood volume \\
swelling (congestive) brain & -arterial vasodilatation (active, passive) \\
& - venous congestion/obstruction. \\
\hline
\end{tabular}
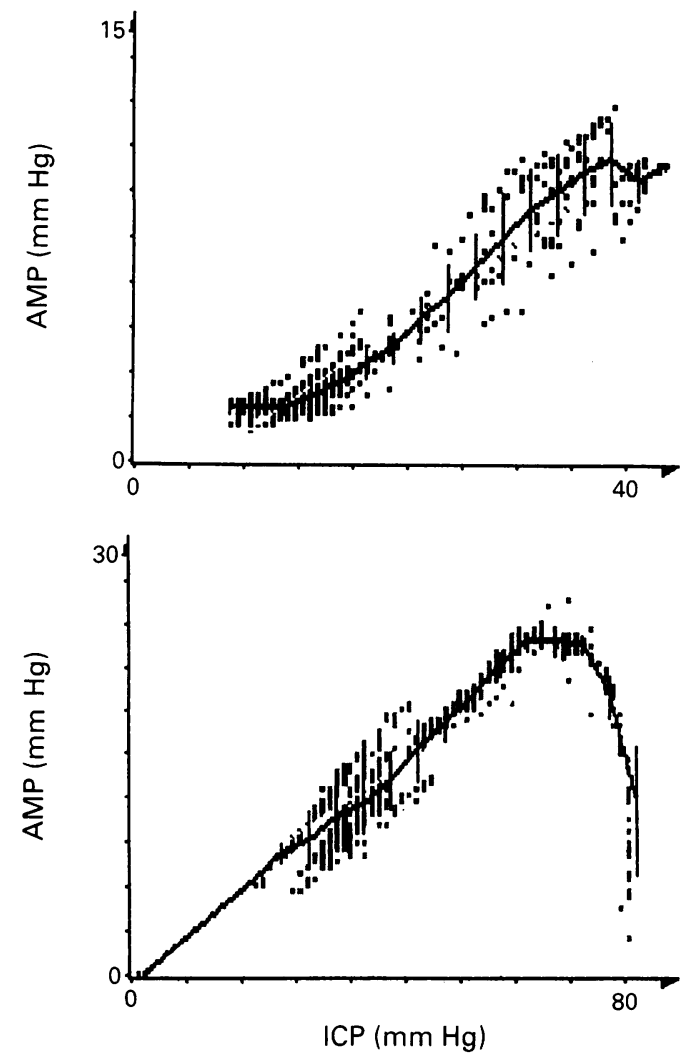

Figure 1 Relationship between mean ICP and amplitude of the ICP waveform in two patients. In the lower trace, there is an upper breakpoint in this relationship when CPP $(M A P-I C P)$ is less than $30 \mathrm{mmHg}$.

reason for the treatment of raised ICP by hyperventilation: an acute reduction of $\mathrm{PaCO}_{2}$ vasoconstricts normal cerebral arterioles and thereby directing blood to focally abnormal areas.

Normally, cerebral blood flow is coupled to cerebral oxidative metabolism via multiple mechanisms involving local concentrations of hydrogen ions, potassium and adenosine for example. Status epilepticus leads to gross cerebral vasodilatation and intracranial hypertension as a result of greatly increased cerebral metabolism and local release of endogenous vasodilator agents. Depression of cerebral energy metabolism by anaesthesia and hypothermia may reduce cerebral blood flow and ICP where there is a large area of the brain with reasonable electrical activity ${ }^{14}$ and where normal flow-metabolism coupling mechanisms are intact as indicated by a reasonable $\mathrm{CBF} \mathrm{CO}_{2}$ reactivity. ${ }^{15}$

Spontaneous waves of ICP are associated with cerebrovascular dilatation. Cerebral blood volume increases during plateau waves (ICP $>50 \mathrm{mmHg}$ for more than 5 minutes) and may be the result in some cases of inappropriate autoregulatory vasodilatation in response to a critical fall in CPP but certainly not in all cases (fig 2). ${ }^{16}$ TCD has revealed that middle cerebral artery (MCA) flow velocity increases pari-passu with $B$ waves $(0 \cdot 5-2 / \mathrm{min}$ ) of ICP (fig 3$) .{ }^{17}$

Finally, gradients of ICP may develop when herniation occurs - transtentorial, subfalcine and foramen magnum. Blockage to the free flow of CSF between intracranial 
Figure 2 Relationships between arterial pressure a plateau wave. $(A B P), C P P, I C P$ amplitude (AMP) during

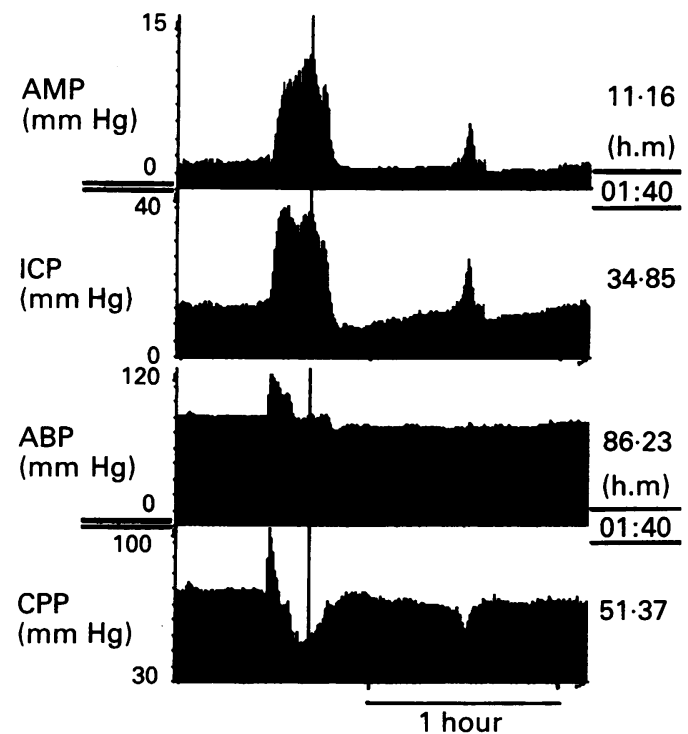

compartments leads to a much greater and more rapid rise in ICP in the compartment harbouring the primary pathology and hence to the final common sequence of transtentorial and foramen magnum coning. When ICP equals arterial blood pressure, angiographic pseudo-occlusion occurs, reverberation, systolic spikes or no flow may be seen on TCD (fig 4). Patients will often satisfy the formal clinical criteria for brainstem death, for which TCD is not a substitute. ${ }^{18} 19$

There is a complex interaction between the properties of the CSF and the cerebral circulations that may be modelled (fig 5)..$^{20}$ The relative contributions of abnormalities of CSF absorption and cerebral blood volume may be approximated by calculating the proportion of CSF pressure attributable to CSF outflow resistance and venous pressure from Davson's equation (ICP $=$ CSF formation rate $\times$ outflow resistance + sagittal sinus pressure) ${ }^{22}$ Phenomena such as the interaction of autoregulation to changing CPP with $\mathrm{PaCO}_{2}$ may be quantified. ${ }^{23}$

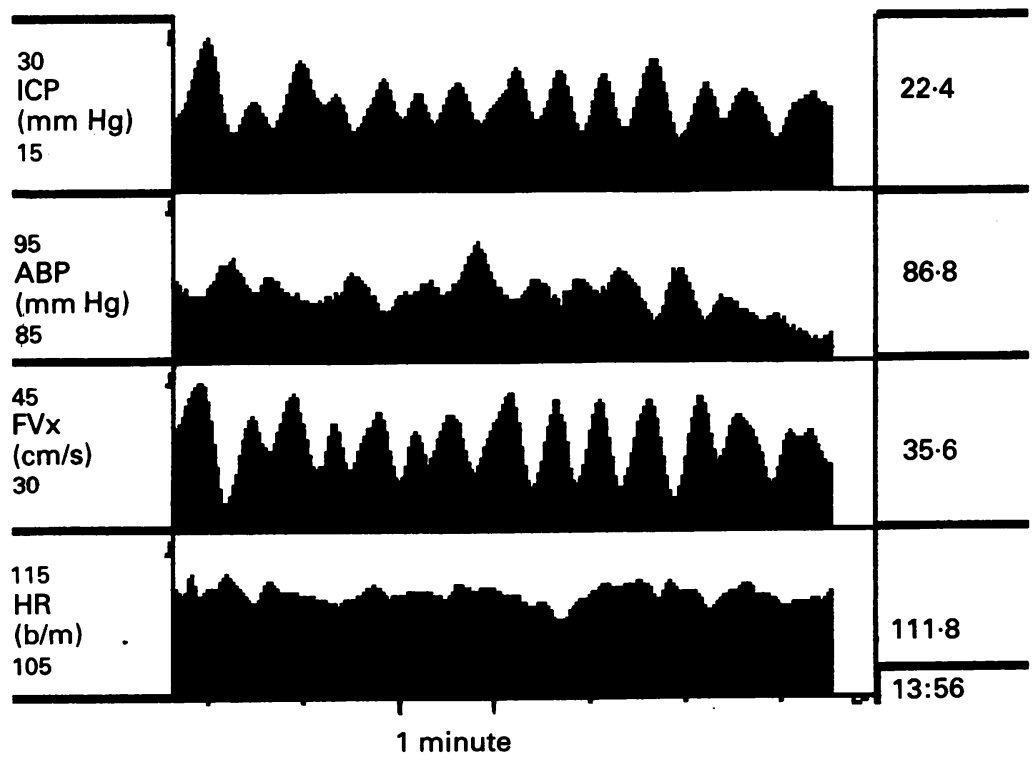

Figure $3 B$ waves of ICP in a head-injured patient and their relationship to similar variations in middle cerebral artery flow velocity compared to fluctuations in arterial blood pressure $(A B P)$ and heart-rate $(H R)$.

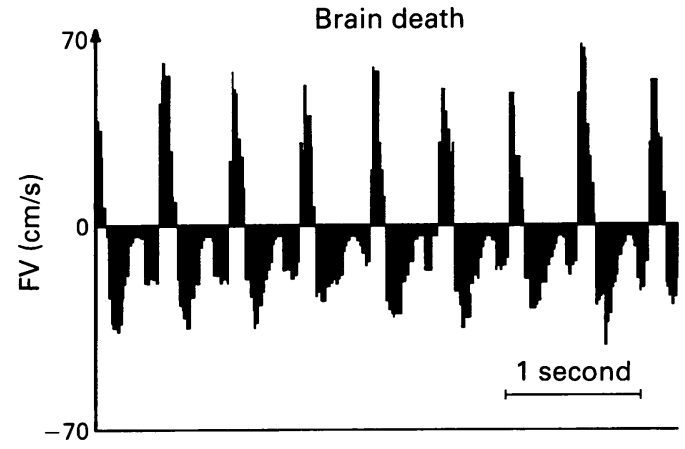

Figure 4 Reversal of middle cerebral artery flow velocity (FV) in a patient who fulfils the criteria for brainstem death.

\section{Monitoring techniques}

A) Clinical features

In the non-trauma patient, there may or may not be a clear history of headache, vomiting and visual disturbance suggestive of papilloedema or a VIth nerve palsy. The absence of papilloedema does not exclude raised ICP in patients with acute or chronic problems: disc swelling was found in only $4 \%$ of head injury patients, $50 \%$ of whom had raised ICP on monitoring. ${ }^{6}$ Even in the $1990 \mathrm{~s}$, it is regrettable that a clear history of raised intracranial pressure may be misinterpreted until the final denouement of disturbance of consciousness and pupillary abnormality or apnoea presents. Only slowly has the danger of lumbar puncture in the differential diagnosis of neurological patients been appreciated by the non-expert. Many of the later signs of raised ICP are the result of herniation: monitoring should detect raised ICP at an earlier stage and hence treat before irreversible damage occurs.

\section{B) CT scanning}

CT scanning may reveal not only a mass, hydrocephalus or cerebral oedema but also evidence of diffuse brain swelling such as absent perimesencephalic cisterns, compressed 3 rd ventricle and midline shift.

\section{C) Invasive methods of ICP monitoring} including CSF infusion tests

The gold standard of ICP monitoring, that was first introduced between $1951,{ }^{2410}$ still remains the measurement of intraventricular fluid pressure either directly or via a CSF reservoir, with the opportunity to exclude zero drift. Subdural fluid filled catheters are reasonably accurate below $30 \mathrm{~mm} \mathrm{Hg}$. A total of $25 \mathrm{mmHg}$ for more than 5 minutes is the usual threshold level at which treatment should be instigated. Risk of infection, epilepsy and haemorrhage is less with subdural than intraventricular catheters but even the latter should be less than $5 \%$ overall. Catheter tip transducers are very useful particularly for waveform analysis, whether placed intraventricularly, subdurally or intracerebrally. Ventricular catheters permit the therapeutic drainage of CSF in cases of ventricular dilatation. In more chronic condi- 


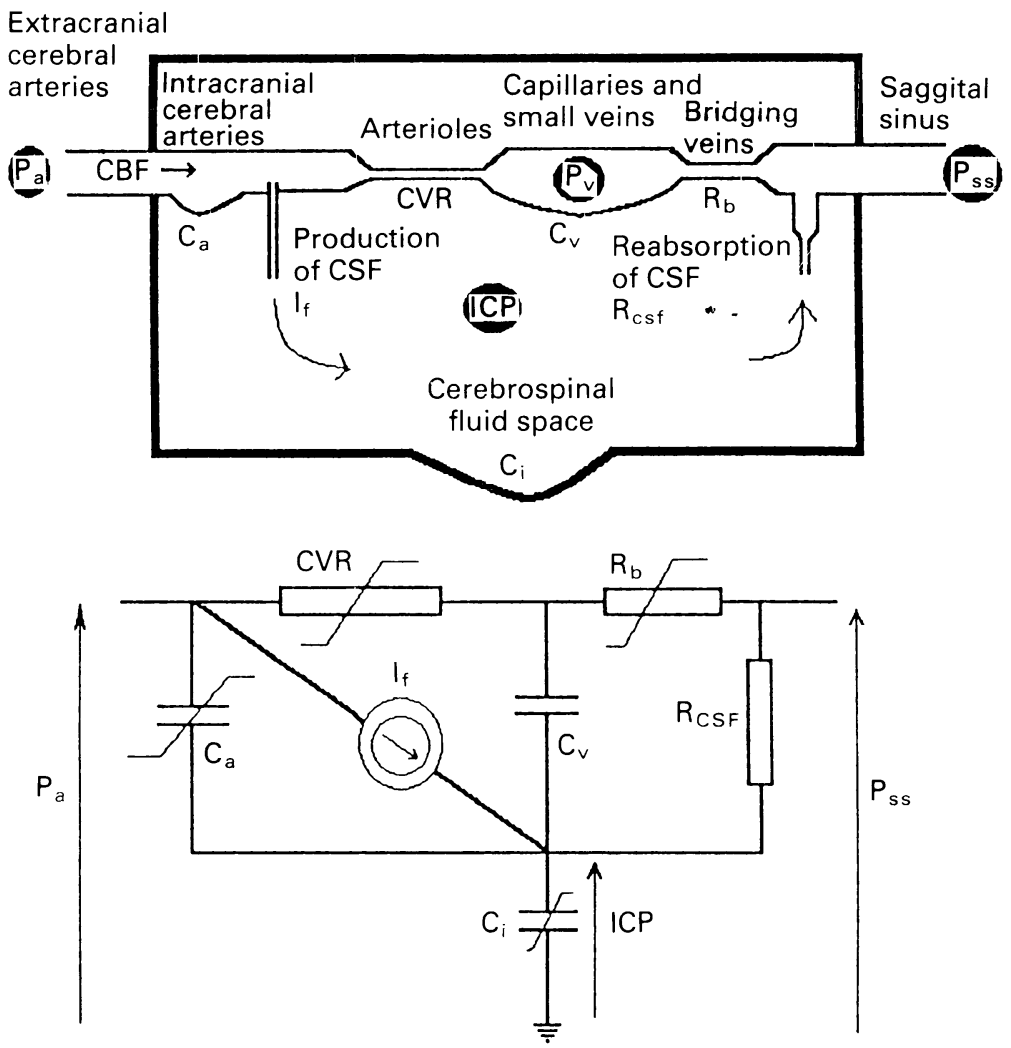

Figure 5 Hydrodynamic model of cerebral blood flow and CSF circulation with the electrically equivalent circuit (for details, see Czosnyka, et al, reference 21).

Figure 6 Relationship between ICP, CPP, ICP amplitude $(A M P)$ and flow velocity (systolic $F V_{s}$ diastolic $F V_{d}$ and amplitude $F V_{a}$ ) during a plateau wave. The amplitude of ICP increases with ICP and decrease in CPP: flow velocity amplitude increases as a result of the fall in diastolic flow velocity.

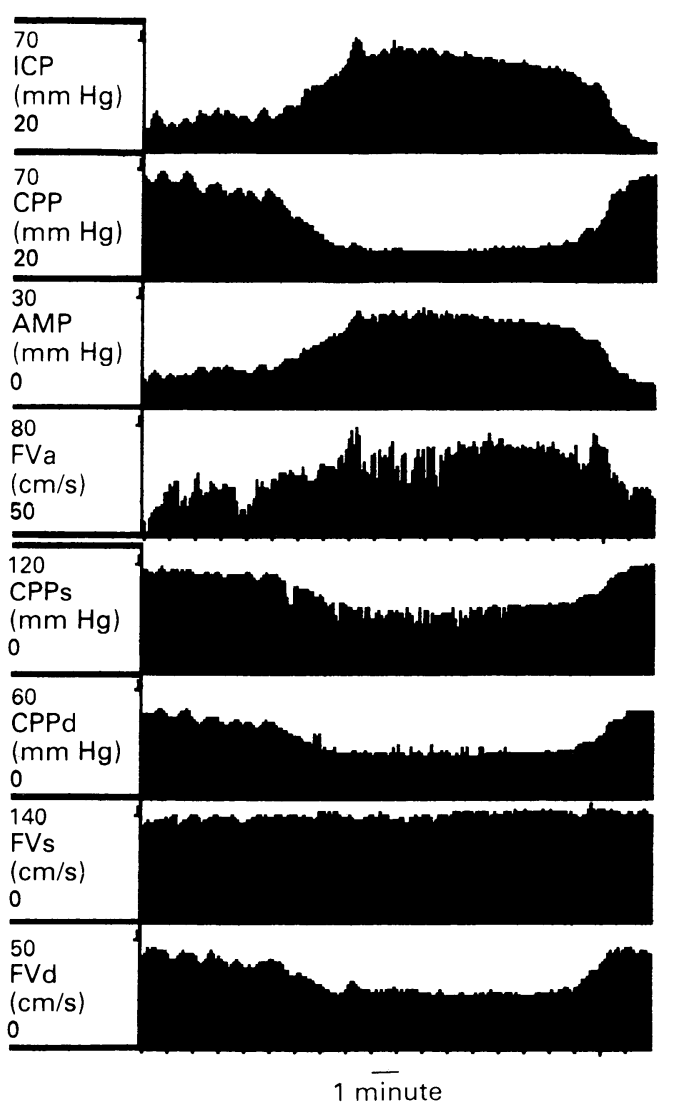

tions of ventricular dilatation, where ICP is not greatly raised, obstruction to CSF absorption may be confirmed by CSF infusion tests (ventricular or lumbar) taking care to adapt the technique to the site of any obstruction. ${ }^{25-27}$ Twenty four hour intracranial pressure monitoring in patients with socalled normal pressure hydrocephalus may reveal a high incidence of $B$ waves during sleep which is a very helpful prognostic sign for the outcome following shunting. ${ }^{28} 29$ Benign intracranial hypertension seldom requires more than CSF pressure monitoring through a lumbar catheter or needle for an hour.

Considerable effort continues into the close analysis of the ICP trace to determine whether it is possible to reveal the mechanism of raised ICP and whether autoregulatory reserve remains intact. ${ }^{30}$ It has been proposed $^{7}$ that congestion or vascular brain swelling may be present when the ratio of the amplitudes of the pulse and respiratory components of the ICP trace exceeds 2, when there is an increase in the high frequency centroid or when there is a high amplitude transfer function for the fundamental harmonic from ABP to ICP. Such a transfer function is calculated from the first Fourier transform of the digitised signal. However, continuous multimodality monitoring is required to draw any safe conclusions and should include some measure of $\mathrm{CBF}$ (for example, TCD) and cerebral metabolism (for example, EEG, jugular venous oxygen). Indices of imminent decompensation would be very helpful but volume-pressure responses, ${ }^{31}$ pressure-volume indices or definition of the contribution of CSF outflow resistance to ICP, ${ }^{22}$ are not suitable for routine clinical use.

\section{D) Non-invasive ICP monitoring}

It would be very helpful to monitor ICP or CPP without invasive catheters. Transcranial Doppler, tympanic membrane displacement and even skull compliance studies have been advocated. It would be very helpful to have answers to the following questions: What is the cerebral perfusion pressure at any given time? What is the relative contribution of each possible mechanism to raised ICP? What features may predict decompensation? Is it possible to have an on-line assessment of cerebrovascular reactivity either to changes in $\mathrm{CPP}$ (autoregulation) or $\mathrm{CO}_{2}$ ? Which therapy or cocktail is best suited to the sum of that individual's 'split-brain' problems?

A noninvasive method that monitored continuously both CPP and CBF autoregulatory reserve would be very helpful in refining management of the swollen brain.

TRANSCRANIAL DOPPLER

Aaslid's description of transcranial Doppler in 1982 permitted bedside monitoring of one index of CBF, non-invasively, repeatedly, and even continuously. ${ }^{3233}$ The problem has been that it is a big tube technique that measures flow velocity in branches of the Circle of Willis, most commonly the middle cerebral 
artery. Changes in velocity may reflect either changes in blood flow or in diameter of the insonated artery. Unfortunately, diameter and flow may not change in complementary directions and great care must be taken with the interpretation. ${ }^{34}$ Low velocity may indicate low flow or arterial dilatation at constant flow. High velocity may indicate high flow or arterial constriction/vasospasm at constant flow. Considerable ingenuity has been expended in analysis of a TCD wave form. The amplitude of the flow velocity pulse wave $\left(F V_{a}\right)$ reflects pulsatile changes in regional $\mathrm{CBF}$ and is dependent on the amplitude of the arterial pressure wave, regional cerebrovascular resistance, the elastance of the capillary bed and the basal cerebral arteries. Aaslid suggested that an index of CPP could be derived from the ratio of the amplitudes of the first harmonics of the arterial blood pressure and of the middle cerebral artery velocity (detected by TCD) multiplied by mean flow velocity. There is a reasonable correlation between the pulsatility index (peak systolicend diastolic FV's/time averaged $F_{\mathrm{m}}$ ) of MCA velocity and CPP after head injury but absolute measurements of CPP cannot be extrapolated. ${ }^{35}$ Nelson et $a l^{66}$ have provided both experimental and theoretical modelling evidence for three haemodynamic phases as CPP falls. Above the lower limit of autoregulation, falls in CPP are masked by arteriolar dilatation, a fall in CVR and gradual increase in $F_{\mathrm{a}}$ so that $C B F$ and $\mathrm{FV}_{\mathrm{m}}$ remain stable. During the transitional phase, $\mathrm{CBF}$ and $\mathrm{FV}_{\mathrm{m}}$ start to fall gradually: CPP in diastole is close to or below the critical closing pressure of the capillaries so that the fall in FV in diastole is greater and $F_{\mathrm{a}}$ increases further. Finally autoregulation becomes exhausted with a rapid fall in CBF and $F V_{m}$ a sharp decrease in $\mathrm{FV}_{\mathrm{a}}$ and an increase in CVR. Where autoregulation is impaired throughout, $\mathrm{CBF}$ and $\mathrm{FV}_{\mathrm{m}}$ fall pressure-passively as CPP is reduced and there is no increase in $\mathrm{FV}_{\mathrm{a}}$. The correlation coefficient between $\mathrm{FV}_{\mathrm{a}}$ and $\mathrm{ABP}$ may provide a continuous on-line index of autoregulatory reserve: as autoregulation becomes exhausted, correlation rapidly moves from negative to positive. The response of the cerebral circulation to stress, such as a period of hypotension, hypercapnia or transient carotid compression may also be assessed. ${ }^{3321}$ Hence, autoregulation and cerebrovascular reactivity may be assessed within the vascular territory supplied by the insonated artery. Comparison of the changes in blood flow velocity in a number of branches of the Circle of Willis with that in the cervical internal carotid artery and with cerebral arteriovenous oxygen difference may help to distinguish vasospasm from hyperaemia at least on a global basis. Vasospasm defined by TCD has been associated with delayed cerebral ischaemia after trauma. ${ }^{37-39}$ Such techniques cannot yet define the proportional contributions of both vasospasm and hyperaemia in the same or different parts of the brain in patients who may have both. Depressed CBF $\mathrm{CO}_{2}$ reactivity was found in one study to cor- relate with very severe brain injury or with extensive focal lesions in MCA distribution. Knowledge of the integrity of the CBF $\mathrm{CO}_{2}$ response was helpful in determining the potential effectiveness of hyperventilation or barbiturates for ICP control. ${ }^{40}$

\section{TYMPANIC MEMBRANE DISPLACEMENT.}

ICP is transmitted via the cochlear aqueduct to the perilymph of the cochlea providing that the aqueduct is patent. Perilymphatic pressure may be assessed indirectly by recording displacement of the tympanic membrane during stapedial reflex contractions elicited by a loud sound. ${ }^{41}$ High perilymphatic pressure displaces the resting position of the stapes footplate laterally, thereby allowing a higher degree of motion in a medial direction, and results in a more inward going tympanic membrane displacement on stapedial contraction. Low perilymphatic pressure will have an opposite effect. A transducer probe attached to a head set is placed in the patient's external auditory meatus and computer based instrumentation allows small movements of the tympanic membrane to be measured when $1000 \mathrm{~Hz}$ of increasing sound pressure level induces stapedial contraction. This very ingenious technique is useful in younger patients with hydrocephalus or benign intracranial hypertension on a sequential basis, provided that a skilled audiologist is available. It does not provide an absolute measure of ICP. It is of no value in patients on ventilators receiving muscle relaxants. The patency of the cochlear aqueduct decreases with age and should be checked with a postural test.

\section{E) Cerebral venous oxygen ${ }^{42} 43$}

Cerebral arterio-venous oxygen content difference should normally be $5-7 \mathrm{ml} / \mathrm{dl}$. Values below $4 \mathrm{ml} / \mathrm{dl}$ indicate cerebral hyperaemia while values above $9 \mathrm{ml} / \mathrm{dl}$ indicate global cerebral ischaemia. Jugular bulb oxygen saturation may be monitored, preferably continuously, with an indwelling catheter. Single measurements of jugular venous oxygen are of little value given the many fluctuations during the day. Overenthusiastic treatment, that on occasion may induce cerebral ischaemia, may be monitored with this technique. Hyperventilation and barbiturateinduced falls in CPP have been shown in individual patients to be counter-productive. An index of regional oxygen metabolism is required. Transcutaneous, transcranial near infra-red spectroscopy is completely noninvasive. ${ }^{44}$ Unfortunately, it is well proven only in neonates and younger children and not yet in older age groups.

F) Cerebral electrical activity

The compressed EEG (cerebral function monitoring) is helpful in deciding whether cerebral metabolic depressants may be indicated in the treatment of intracranial hypertension. ${ }^{14}$ Such drugs will obviously not be helpful if the EEG is flat or greatly reduced in amplitude. 
Table 3 Indications for ICP monitoring

Head injury

(a) being artificially ventilated:

-coma with compression of 3rd ventricle and/or reduction in perimesencephalic cisterns on $\mathrm{CT}$, coma following removal of intracranial haematoma - coma with abnormal motor response as the best reaction,

- coma with midline shift/unilateral ventricular dilatation,

-multiple injury including severe chest wall injuries. -early seizures not easily controlled. -refractory hyperpyrexia.

(b) uncertainty over surgery for small haematoma/multiple lesions.

Intracerebral and subarachnoid haemorrhage - coma

- postoperatively following intraoperative complications, -hydrocephalus.

Coma with brain swelling

—-metabolic,

-infective (see Table 1)

Hydrocephalus and benign intracranial hypertension

(Adapted from references 4, 7, 42)

\section{Management strategies}

1) Emergency resuscitation and diagnosis

Patients who are rapidly deteriorating or already in coma require immediate resuscitation if necessary with intubation and ventilation followed by a diagnostic CT scan. An intravenous bolus of mannitol $(0.5 \mathrm{gms} / \mathrm{kg}$ over 15 minutes may be required if there is evidence of coning such as pupillary dilatation.) Acute ventricular dilatation demands immediate ventricular drainage-bilateral if the lesion is midline. Hyperacute ventricular dilatation following subarachnoid haemorrhage or in association with a third ventricular lesion need not be gross to cause death. Surgical clots require removal and abscesses require tapping.

\section{2) Post-acute management}

Many neurosurgical units worldwide still manage patients without the help or hindrance of ICP monitoring. The nihilistic argument is that ICP monitoring has not been clearly shown to improve outcome and sequential CT scanning provides sufficient information. Treatment for raised ICP has not greatly advanced over the past two decades and can be applied pragmatically. The alternative school of thought argues that ICP monitoring should be selective (table 3 ) based in part on the initial CT scan. However, in addition such monitoring is very educational and greatly assists general nursing and medical care; transport of a patient

Table 4 Potential problems exacerbating raised intracranial pressure

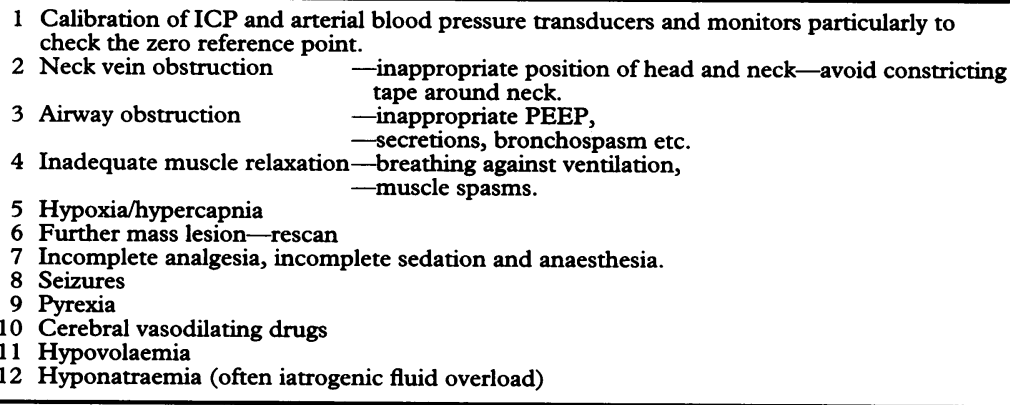

between ICU and CT scanning too often involves well documented risks of hypoxia and hypotension; ICP therapy should not be used as a blunderbuss but needs to be selectively targetted if it is not to be counter-productive, and new treatments are emerging very rapidly. Clinical trials based on outcome studies at six months in such heterogeneous groups of patients may easily miss useful benefits. ${ }^{45}$ To treat raised ICP, it must first be identified, avoidable factors prevented or treated and finally active treatment instigated, hopefully based on our understanding of the individual mechanism involved. ICP should be treated before herniation occurs-clinical signs particularly in patients on a ventilator are just too crude. Knowledge of ICP may help with prognosis and counselling of relatives: in one series of diffuse head injuries, where ICP persistently exceeded $20 \mathrm{mmHg}$, almost all the patients died compared with a mortality rate of $20 \%$ in those where ICP could be kept below $20 \mathrm{mmHg}$ with treatment. ${ }^{46}$

\section{3) Prevention of intracranial hypertension: general medical and nursing care-avoidable factors.}

Simple measures need to be checked (table $4) .^{72}$ Ideally the position of the patient should minimise any obstruction to cerebral venous drainage by head-up tilt whilst avoiding any fall in cardiac output or carotid arterial blood pressure. Direct measurement of global CBF and CPP suggests that head-up tilt of up to $30^{\circ}$ is safe but careful scrutiny should be kept of CPP in individual patients. ${ }^{47-50}$

Hypovolaemia should be avoided, contrary to some historical teaching. The evidence is most clear cut in patients after subarachnoid haemorrhage: dehydration particularly when coupled with hyponatraemia increases the risk of cerebral infarction. ${ }^{51}$ Patients with CT evidence of raised ICP are already at greater risk of hypovolaemia after SAH. ${ }^{52}$ Dehydration increases the risk of hypovolaemia which may be revealed only when the patient is given an anaesthetic agent, for example, for an orthopaedic procedure or as part of a regime to control raised ICP. A stable circulation must be maintained, ${ }^{53}$ if necessary with colloid and inotropes (dobutamine or dopamine for its renal sparing action). However, overenthusiastic hypertensive-hypervolaemic therapy remains very controversial in the context of head injury with its multiple pathology and uncertainty over the integrity of the blood-brain barrier. ${ }^{54-56}$ Systemic hypertension should not be treated directly with agents such as sodium nitroprusside. Sodium nitroprusside impairs autoregulation and increases the risk of boundary zone infarction. ${ }^{57}$ The cause of hypertension, for example, pain or retention of urine, should be looked for.

The majority of neurosurgical patients with hyponatraemia do not have inappropriate secretion of $\mathrm{ADH}$ and it is unwise to use fluid restriction to treat them even if they do. ${ }^{5158}$ 
A useful dictum in neurosurgery is that blood volume comes before plasma sodium levels. Moderate hyponatraemia impairs cerebrovascular reactivity experimentally to both hypercapnia and hypotension but does not augment the cerebrovascular effects of experimental SAH. ${ }^{59}$ A spectrum of abnormalities give rise to hyponatraemia following $\mathrm{SAH}$, for example: initial natriuresis leading to volume depletion, $\mathrm{ADH}$ secretion stimulated both by stress and volume depletion, $\mathrm{ADH}$-induced water retention, steroid- and sympatheticinduced effects on the kidney and possible release of atrial natriuretic factor (both cardiac and cerebral in origin) and digoxin-like substance.

Seizures may be difficult to recognise when the patient is paralysed and ventilated. Episodes of pupillary dilatation with increases in arterial blood pressure and ICP are suggestive.

Pyrexia not only increases cerebral metabolism and hence cerebral vasodilatation but also cerebral oedema. Severe hypothermia was used historically to treat raised ICP but it has become clear more recently that mild hypothermia of a few ${ }^{\circ} \mathrm{C}$ only will reduce cerebral ischaemia for reasons that are not yet clear. ${ }^{13}$ Hyperglycaemia should be avoided. There is considerable evidence that cerebral ischaemia and infarction is made worse by hyperglycaemia and the use of high glucose solutions is contraindicated unless there is significant evidence of benefit in a particular metabolic encephalopathy..$^{60} 61$

\section{Osmotic diuretics}

Intravenous mannitol is invaluable as a first aid measure in a patient with brain herniation as a result of raised ICP. Its more prolonged use and mechanisms of action remain contentious issues. Osmotherapy began experimentally with hypertonic saline and then urea, entering neurosurgical practice with $30 \%$ urea in 1958. A maximum fall in ICP occurs within 30 minutes of starting urea, and the effect lasts for up to three hours but with the possibility of subsequent rebound. ${ }^{62}$ Conceptually, the mechanism was thought to be osmotic extraction of water across the intact blood-brain barrier acting as a semipermeable membrane. Experimentally, urea shrank normal rather than oedematous brain. ${ }^{63}$ Entry of urea into the oedematous brain through a 'defective' barrier would take water in and thereby account for rebound. Overenthusiastic bolus administration of an osmotic diuretic may cause abrupt systemic hypertension, an increase in cerebral blood volume if autoregulation is defective or its upper limit is exceeded and promote herniation rather than the reverse. ${ }^{64}$

More recent studies indicate that mannitol, given time, removes water from both normal and oedematous brain, be it ischaemic or interstitial (Marmarou's infusion model). ${ }^{65-67}$ The oedematous area around many mass lesions may still have an intact blood-brain barrier at least to the conventional high molecular weight tracers. The time course is slow and does not account for the immediate effect of mannitol on ICP. In patients with peritumoural oedema, mannitol causes withdrawal of water mainly from brain areas where the barrier is impaired as judged by $T 1$ MRI and in vitro measurements of brain water content. ${ }^{68}$ However, mannitol may accumulate in oedematous white matter with repeated doses. ${ }^{69}$

The more immediate effects of intravenous mannitol include a fall in whole blood viscosity with reduced red cell rigidity and corpuscular volume, an increase in brain compliance and possibly cerebral vasoconstriction. ${ }^{70-72}$ Experimental perivascular administration of mannitol evokes vasodilatation. The cerebral vasoconstriction with intravascular bolus administration was short-lived-in the cat, both pial arteriolar diameter and ICP returned to normal within 30 minutes and thereafter both increased, pari-passu with changes in blood viscosity. ${ }^{72}$ Administration over 15 minutes produced no change in pial arteriole or venular diameter in another study. ${ }^{73}$ Current studies in patients are using transcranial and laser Doppler to re-examine these conflicting reports. Why should a sudden change in blood viscosity evoke acute transient vasoconstriction? Chronic changes in blood viscosity by plasma exchange, without alterations in haemoglobin or arterial oxygen content do not change steady-state CBF in humans. ${ }^{74}$ Patients with high plasma viscosity or with high viscosity due to large numbers of white cells do not have low CBF values. In a series of patients with haematological diseases but no evidence of cerebrovascular disease, arterial oxygen content was the major determinant of CBF-blood viscosity per se had no significant effect on CBF. ${ }^{75}$ If a single blood vessel is considered, the apparent viscosity of blood diminishes in proportion to its radius as a result of the marginal sheath of low viscosity and axial flow of red cells. ${ }^{76}$ The width of this sheath is greatest relatively in small vessels. Furthermore, apparent viscosity increases with falling velocity. Hence with pial arterial dilatation, lccal blood viscosity will rise both because of the increased proportion of red cells and as a result of the reduction in flow velocity if tissue perfusion flow remains constant. Simplistically, according to Poiseuille, as viscosity is reduced deliberately, so the pressure gradient along the pial arteriole under observation falls. Hence, the distal intravascular pressure increases if the proximal pressure remains constant. The distal end of the arteriole therefore constricts if autoregulatory mechanisms such as the Bayliss effect are intact. 'Viscosity' autoregulation should depend on pressure autoregulation unless there is a separate endothelial mechanism that is flow- or viscosity-sensitive. Alternatively, mannitol may transiently increase CBF, increase oxygen delivery and wash out local vasodilators such as adenosine. ${ }^{72}$ Vasoconstriction then follows. Extracellular hyperosmolarity is a potent 
cerebral vasodilator and it is remarkable that the intravenous vasoconstrictor effect of mannitol so completely dominates the acute cerebrovascular effect. If the viscosity mechanism is apposite, it will depend upon the distribution gradient of intravascular pressures along the cerebrovascular tree which may not be easy to predict with different pathologies and cerebral perfusion pressures. Certainly the reported effects of mannitol on CBF are not easy to rationalise. ${ }^{77-80}$ In severely head injured patients in whom autoregulation was absent, intravenous mannitol caused an increase in cerebral blood flow and no reduction in ICP. ${ }^{81}$ ICP was reduced in those patients where autoregulation was intact. However, in patients with unruptured aneurysms and in the majority of whom autoregulation was intact presumably, mannitol (bolus or infusion) increased CBF for many hours. ${ }^{80}$ More regional assessments of CBF suggest that mannitol may stablise $\mathrm{pH}$ and $\mathrm{CBF}$ in regions of moderate but not severe ischaemia. ${ }^{82}$ Other suggested mechanisms for the effect of mannitol include movement of water from CSF into capillaries and scavenging of free radicals. ${ }^{83}$ Plasma hyperosmolality rapidly reverses the interstitial fluid pressure/CSF pressure gradient and there is a rapid volume shift within $30 \mathrm{~min}$ utes from CSF into brain tissue. ${ }^{131}$

Many attempts have been made to rationalise how much mannitol may be given and when, for more prolonged effects. ${ }^{84}{ }^{85}$ In practice, mannitol tends to be given as an intermittent bolus whenever the individual patient's ICP rises significantly above the threshold of $25-30 \mathrm{mmHg}$. The effects of mannitol may be potentiated by adding frusemide.$^{85}$ It is crucial to avoid dehydration and latent hypotension with careful attention to fluid balance. Colloid with an adequate plasma half life (albumin, hetastarch for example) should be combined with careful electrolyte replacement. Another dose of mannitol should not be given if osmolarity exceeds $330 \mathrm{mmol} / \mathrm{l}$ for fear of tubular damage and renal failure. Repeated doses of mannitol should not be given unless an ICP monitor is in place. Some authors continue to recommend glycerol for prolonged osmotherapy. ${ }^{86}$

\section{Hyperventilation, the buffer THAM and indomethacin}

The cerebral vasoconstrictor effect of hypocapnia, induced by hyperventilation, does not persist much beyond a day, probably in part because the bicarbonate buffering mechanisms within the brain and cerebrovascular smooth muscle themselves readjust to return extracellular and intracellular $\mathrm{pH}$ nearer to the original values. ${ }^{87}$ This phenomenon has now been confirmed in vivo in normal subjects by magnetic resonance spectroscopy. Neurosurgical patients with healthy lungs and systemic circulation often hyperventilate spontaneously down to a $\mathrm{PaCO}_{2}$ of $30 \mathrm{mmHg}{ }^{6}{ }^{42}$ More enthusiastic hyperventilation may precipitate cerebral ischaemia with EEG slowing, CSF lactic acidosis and a cerebral arterio-venous oxygen content difference $>9 \mathrm{ml} / \mathrm{dl}$. Arterial blood pressure may be reduced by the combination of dehydration and aggressive hyperventilation. Finally, weaning from the ventilator may be more difficult and prone to "rebound" intracranial hypertension: the brain's buffering mechanisms have to readjust back again. Finally, cerebrovascular reactivity to $\mathrm{CO}_{2}$ may be absent in some patients after head injury, but such reactivity is seldom measured before hyperventilation is started. TCD is a simple way of assessing $\mathrm{CO}_{2}$ reactivity. In one study, controlled hyperventilation used prophylactically did not improve outcome but did prolong the recovery phase. ${ }^{88}$ Hence there is growing awareness that hyperventilation be used sparingly, for example, to treat persistent ICP waves.

CSF lactate accumulation and CSF acidosis occur after head injury. ${ }^{89} 90$ Both severity of injury and the proportion of patients with a poor outcome are related to high and increasing CSF lactate levels. Cerebral tissue lactic acidosis is related to secondary brain damage following a primary insult such as cerebral ischaemia even if moderate acidosis per se has no persisting effect on normal neurons. Akiota et $a l^{91}$ found that the intravenous buffer tris hydroxymethyl aminomethane (THAM) ameliorated both the CSF acidosis and brain swelling following epidural balloon compression of the brain in dogs. In 1970, Gordan and Rossanda ${ }^{92}$ suggested that hyperventilation might be beneficial as the result of compensation of CSF acidosis but only at very low arterial $\mathrm{pCO}_{2}(20-25 \mathrm{mmHg})$ that is now proposed to produce severe cerebral vasoconstriction and in some individuals cerebral ischaemia. THAM, after intravenous administration, equilibrates with the intracellular and extracellular spaces in the body as well as with CSF. Evidence is accumulating both experimentally and in humans that THAM is at least as effective as mannitol in reducing experimental oedema in the brain and lowering ICP after head injury. ${ }^{9394}$ THAM reduces the demand for mannitol and CSF drainage. In the most recently published randomised prospective clinical trial, ${ }^{94}$ a total of 149 patients with severe head injury (Glasgow Coma Scale $\leq 8$ ) were randomly assigned to either a control or a THAM group. Both groups of patients matched in terms of clinical parameters including age, sex, number of surgical mass lesions, number in each Glasgow scale stratum and the first ICP measurement. All patients were treated by standard management protocols, intubated, mechanically ventilated, and maintained in the $\mathrm{PaCO}_{2}$ range of $32-35 \mathrm{~mm} \mathrm{Hg}$ for 5 days. THAM was administered as a 0.3 $M$ solution in an initial loading dose (body weight $\times$ blood acidity deficit, average $4 \cdot 27$ $\mathrm{cc} / \mathrm{kg} /$ hour) given over two hours, followed by constant infusion of $1 \mathrm{ml} / \mathrm{kg} /$ hour for five days. Outcome was measured at three, six and 12 months post injury. Although analysis indi- 
cated no significant difference between these two groups at three months, six months or one year, there was a difference regarding ICP. The time that ICP was above $20 \mathrm{mmHg}$ in the first 48 hours after injury was less in patients treated with THAM. Also the number of patients requiring barbiturate coma was significantly less in the THAM group ( $5 \cdot 5 \%$ versus $18 \cdot 4 \%)$. The authors concluded that THAM ameliorated the deleterious effects of prolonged hyperventilation, was beneficial in ICP control and further study of dose and timing of administration was warranted.

The cerebrovascular response to hypercapnia may be manipulated in other ways. It has been known since 1973 that the cerebrovascular $\mathrm{CO}_{2}$ response is blocked by indomethacin in doses that partly inhibit brain cyclo-oxygenase activity in vivo. ${ }^{95}$ Cerebral venous pressure is very significantly reduced suggesting that ICP is reduced. That observation was not used clinically because of fear that indomethacin was inhibiting production of prostacyclin and that might be counterproductive. Certainly, cerebral oxygen delivery is seriously impaired when indomethacin is given to very young animals or to very pre-term infants undergoing treatment for patent ductus arteriosus. ${ }^{96}$ However, in five patients with injury with cerebral contusion and oedema in whom it was not possible to control ICP by hyperventilation and barbiturate sedation, indomethacin (bolus injection of $30 \mathrm{mgs}$ followed by $30 \mathrm{mg} /$ hour for 7 hours) reduced ICP below $20 \mathrm{mmHg}$ for several hours. ${ }^{97} \mathrm{CBF}$ was reduced at two hours without any changes in cerebral arteriovenous oxygen or lactate differences. Rectal temperature also fell from 38.6 to $37 \cdot 3^{\circ} \mathrm{C}$. Hence a more substantial trial of indomethacin appears warranted, perhaps avoiding young children until further experience is accumulated. Inhibition of nitric oxide synthesis also blocks the cerebrovascular $\mathrm{CO}_{2}$ response but may also increase focal cerebral infarction in the rat middle cerebral occlusion model.

\section{Continuous CSF drainage and surgical decompression}

External ventricular drainage via a catheter or reservoir is a rapid procedure in an emergencly in a patient with hydrocephalus. Biventricular drainage is required for 3rd ventricular lesions that occlude both Foramena of Munro. Colloid cysts are best dealt with as the primary procedure unless the patient is in extremis. Patients with communicating hydrocephalus or benign intracranial hypertension may be temporarily controlled by lumbar drainage through an indwelling catheter. It is unkind, unnecessary and less effective to use repeated lumbar punctures. It is becoming recognised that permanent CSF drainage via lumbar peritoneal shunts may be complicated by secondary descent of the cerebellar tonsils in patients with no previous evidence of a Chiari malformation. ${ }^{98}$ In all cases of external drainage, CSF should be drained gradually against a positive pressure of $15-25 \mathrm{~cm} \mathrm{H}_{2} \mathrm{O}$ to avoid unrestrained drainage. In the case of a posterior fossa tumour, upward coning may be precipitated if the supratentorial ventricles are drained too precipitately. In patients with a hemisphere mass causing midline shift and contralateral hydrocephalus, drainage of that ventricle may make the shift worse. In patients with diffuse brain swelling, the ventricles are small and not always easy to cannulate. Stereotactic techniques are useful but not appropriate in an emergency. Even where ICP is controlled by drainage against a pressure $15-25 \mathrm{cms}$ $\mathrm{H}_{2} \mathrm{O}$, such a ventricular catheter readily becomes blocked and is seldom a satisfactory technique per se. CSF drainage alone is the optimal method of controlling intracranial hypertension in patients with subarachnoid haemorrhage where the cause is often disturbance of the CSF circulation but there is probably an increased risk of rebleeding. CSF drainage is used as a diagnostic technique to assess patients in the poorer SAH grades. When they improve early surgery should be considered.

Removal of bone flaps or subtemporal decompressions are performed much less frequently nowadays. ${ }^{99}$ Patients with large meningiomas may have a smoother postoperative course if a flap is removed electively at the end of the operation rather than as an emergency a few hours later. Benign intracranial hypertension can be treated by a combination of optic nerve sheath fenestration and lumbar peritoneal or cisterno-peritoneal shunting: subtemporal decompressions are rarely indicated. Babies with complex forms of craniosynostosis may require craniofacial surgery to expand the volume of the skull. Slit ventricle syndrome for shunt-induced CSF overdrainage may be managed by use of siphon control devices or programmable valves-subtemporal decompression is seldom required. This procedure was sometimes followed by temporal lobe epilepsy.

There is a very restricted place for decompressive craniotomy following head injury and there is the potential to do considerable harm..$^{99} 100$ With a very tight brain, opening the dura induces herniation through the defect. Cerebral venous drainage from the herniated brain obstructs and further brain swelling ensues with infarction. Experimentally, craniectomy facilitates formation of hydrostatic brain oedema as might be expected from consideration of Starling's equation. ${ }^{101}$ Craniectomy may be considered in young patients without evidence of diffuse axonal injury (high Glasgow Coma Score on admission) and evidence of diffuse swelling. ${ }^{102}$ For paediatric encephalopathies, Kirkham makes a case for performing decompression earlier rather than later and certainly before the EEG disappears. ${ }^{103}$

\section{Steroids, free radical scavengers and the} lazaroids

The mechanism of the remarkable effect of glucocorticoids such as dexamethasone on 
focal, relatively chronic cerebral lesions remains incompletely understood. Patients deteriorating with a cerebral tumour or an abscess rapidly improve within 24 hours. It is not yet proven whether steroids help traumatic cerebral contusions. ICP waves and compliance improve together although mean ICP and water content take days longer to subside. Brain biopsy for tumour is much safer after at least three days of dexamethasone (10-20 mgs loading dose; $4 \mathrm{mgs}$ four times a day thereafter) particularly when combined with stereotactic biopsy techniques. Care should be taken to counsel patients about the side effects of steroids even with short courses.

Much controversy has surrounded the use of very high dose steroids in head injury but careful controlled trials have shown no benefit and in one study the outcome of the treatment group was worse. ${ }^{104-108}$ However, even higher doses started within a few hours of injury are currently under scrutiny. This rationale is based on trials in spinal cord injury of methylprednisolone ( $30 \mathrm{mgs} / \mathrm{kg} /$ day) which showed a modest benefit in the group where it was started within eight hours of injury.

One purported mechanism of action for steroids involves lipid peroxidation and free radicals. ${ }^{109110}$ Oxygen is needed for aerobic life but it has toxic properties. All organisms are subject to oxidative stress as up to $2 \%$ of oxygen consumed by the brain, for example, is used to form semi-reduced oxygen intermediates: superoxide, hydrogen peroxide and hydroxyl free radicals. These may be used as part of normal biochemistry or if the safety mechanisms fail-superoxide dismutase, catalase, glutathione peroxidase, glutathione, vitamin $E$ and ascorbate-then such reactive oxygen species may attack nucleic acids, proteins, carbohydrates and particularly lipids in the brain. Ferrous iron from blood clots is also active along with such reactive oxygen species. Cerebrovascular effects of acute hypertension and subarachnoid haemorrhage may involve free radical mechanisms damaging the endothelium. Non-glucocorticoid steroid analogues of methylprednisolone as well as methylprednisolone itself weakly inhibit lipid peroxidation. The 21-aminosteroids (the antioxidant family known as the lazaroids) are potent inhibitors of lipid peroxidation and have a vitamin $E$ sparing effect. ${ }^{111}$ Various experimental models of head and spinal injury and focal or global ischaemia have shown a variable degree of protection after treatment with the lazaroid U-74006F so that it is now undergoing large scale clinical trials in head injury and subarachnoid haemorrhage. Recently, the steroid component of the lazaroid molecule has been replaced by the anti-oxidant ring structure of vitamin $\mathrm{E}$. U78517F has greater in vitro lipid anti-oxidant properties than $\mathrm{U}-74006 \mathrm{~F}$. It is interesting that the iron chelator desferrioxamine may be helpful in treating the coma of cerebral malaria and experimental vasogenic oedema. Early results in severe head injuries with the oxygen radical scavenger-poly- ethylene glycol conjugated superoxide dismutase-have recently been reported but a much larger trial is required to establish efficacy. ${ }^{112}$

\section{Cerebral metabolic depressants: excitotoxic amino acid antagonists}

The cerebral metabolic depressant effect of deep hypothermia is now seldom used except during cardio-pulmonary bypass and total circulatory arrest. Such a technique may be used for complex basilar aneurysms where interventional radiological techniques are inappropriate. Brain energy metabolism is depressed more conveniently by hypnotic agents including barbiturates, etomidate, propofol, althesin and gamma hydroxybutyrate. Unfortunately all such agents have side effects, the most relevant of which is systemic hypotension, often compounded by dehydration or hypovolaemia. It is essential to maintain a normal arterial blood pressure and not allow CPP to fall. Central venous pressure monitoring is required. One factor maintaining CPP in patients with raised ICP may be the Cushing mechanism-lower the ICP and CPP falls.

Hypnotic agents depress cerebral oxidative metabolism and hence lower CBF, CBV and ICP. However, cerebral electrical activity and normal coupling mechanisms between metabolism and flow must be present if barbiturates are to lower ICP. ${ }^{14} 1542$ Normal flow metabolism coupling mechanisms may be assessed by the cerebrovascular response to $\mathrm{CO}_{2}$. Short-term protection during aneurysmal surgery with barbiturate or propofol is widely used. Synergy with even moderate hypothermia may be helpful provided MAP is maintained. ${ }^{42}$ After initial reports of the effectiveness of short acting barbiturates in lowering ICP after head injury, three controlled trials have failed to show any overall significant improvement of outcome or reduction in number of patients dying with intracranial hypertension. ${ }^{114-116}$ Such trials involved heterogeneous groups of patients, however, and a treatment benefit in a sub group may have been missed.

In the UK, althesin has been withdrawn even though its idiosyncratic allergic problems would not have been a contra-indication in the intensive care environment. Etomidate blocks steroidogenesis but it is apparently still used in the USA as an intraoperative protection agent by combining it with dexamethasone postoperatively for a few days. ${ }^{117}$ Gammahydroxybutyrate drops blood pressure and its administration involves a considerable sodium load. ${ }^{118}$ Propofol (di-isopropylphenol) is widely used but care has to be taken to avoid hypotension. Propofol also has free radical scavenging effects. ${ }^{119}$ The ideal hypnotic agent awaits development. In the patient with cardiovascular instability, lignocaine $(1.5 \mathrm{mg} / \mathrm{kg}$ iv) may have a place in lowering ICP. ${ }^{120}$ This dose is as effective as thiopentone $(3 \mathrm{mg} / \mathrm{kg}$ iv).

Epilepsy has long been known to increase ICP and increase the risk of cerebral ischaemia as a result of a massive increase in 
cerebral electrical activity and oxidative metabolism: both metabolic demand and CPP are embarrassed. Seizures must be treated aggressively. Over the last decade, however, a more focal phenomenon has been revealed: inappropriate hypermetabolism in small areas of the brain in association with local release or failed reuptake of excitotoxic amino acids such as glutamate. ${ }^{121} 122$ For example, subdural haemorrhage in the rat is accompanied by increased glutamate concentrations in the hippocampus with increased local cerebral glucose utilisation and late ischaemic brain damage. An NMDA antagonist will protect against such damage ${ }^{123}$ just as NMDA antagonists reduce delayed neuronal loss and the volume of cerebral infarction after middle cerebral artery occlusion, provided such agents are given prophylactically or in some cases within an hour of occlusion. ${ }^{124} 125$ The therapeutic window of opportunity is very short unless it is surmised that glutamate release occurs at various times after a head injury, not just at the moment of impact. Such impressive experimental data has led to Phase I and II trials of glutamate receptor antagonists in patients after severe head injury. The results are awaited with keen interest. Ironically, that old-fashioned treatment for severe head injuries-rectal magnesium chloride-is now known to be a noncompetitive NMDA receptor antagonist and reduces the infarct volume after middle cerebral occlusion in the rat. ${ }^{126}$

\section{Targetted therapy}

It is clear that there are many causes of raised ICP. The Edinburgh school has attempted ${ }^{7}$ to define which therapy should be selected for each cause of intracranial hypertension. They suggest that hypnotic agents may be most logically targetted at younger patients with diffuse congestive brain swelling with preserved cerebral electrical activity, jugular venous oxygen saturation over $75 \%$, a pulserespiratory ratio in the ICP trace of over 2 , preserved $\mathrm{CBF} \mathrm{CO}_{2}$ reactivity and absence of a diastolic notch on TCD recordings of MCA velocity. Mannitol may be best used in patients of any age with focal lesions, a low cerebral perfusion pressure and reasonably preserved autoregulation. If arterial blood pressure is low despite colloid then inotropic agents such as Dobutamine or dopamine should be used. SAH with raised ICP is best managed by CSF drainage accepting that there is probably an increased risk of rebleeding.

\section{Children}

The management of raised ICP in childhood must take account of a number of factors. ${ }^{4127}$ The critical values for ICP, ABP and CPP are lower, the younger the child. The normal ICP in the newborn is probably of the order of 2-4 mmHg. ABP at birth is about $40 \mathrm{mmHg}$, $80 / 55$ by one year and $90 / 60$ during the early school years. CPP rises from $28 \mathrm{mmHg}$ at 28-32 weeks gestational age of $37.5 \mathrm{mmHg}$ at normal full-term. In the neonate, much lower CBF values may be tolerated for longer. Many of the pathologies differ from the adult including birth asphyxia, posthaemorrhagic ventricular dilatation, craniocerebral disproportion and the many metabolic and infective encephalopathies. Hyperaemia plays a greater role as a cause of raised ICP in children after head injury than in adults. ${ }^{128}{ }^{129}$ The NIH Traumatic Data Bank of severe head injuries revealed that diffuse brain swelling occurs twice as often in children (aged 16 years or younger) as in adults. A total of $53 \%$ of children with diffuse swelling died compared with a mortality rate of $16 \%$ in those without. The skull may expand in children where fusion of the sutures has not occurred. Controlled trials of therapy in the various pathologies are made difficult by the very small numbers of patients seen in each centre. As with adults, there is a wide diversity of opinion on the use of barbiturate coma, steroids and mannitol. Even fluid restriction still has its advocates in the neonates, and for inappropriate secretion of $\mathrm{ADH}$. The dangers of fluid restriction, based on assuming that SIADH is the common cause of hyponatraemia after intracranial insults, have been documented very clearly in studies of adults after SAH.

\section{Summary}

This review has been written at an unfortunate time. Novel questions are being asked of the old therapies and there is an abundance of new strategies both to lower ICP and protect the brain against cerebral ischaemia. In the United Kingdom, the problem is to ensure that appropriate patients continue to be referred to centres where clinical trials of high quality can be undertaken. One of the success stories of the past decade has been the decline in the number of road accidents as a result of seat belt legislation, improvements in car design and the drink/driving laws. Hence, fortunately there are fewer patients with head injuries to treat and it is even more important that patients are appropriately referred if studies to assess efficacy of the new strategies are not to be thwarted. The nihilistic concept that intensive investigation with ICP monitoring for patients with diffuse head injury or brain swelling following evacuation of a haematoma or a contusion has no proven beneficial effect on outcome, requires revision. A cocktail of therapies may be required that can be created only when patients are monitored in sufficient detail to reveal the mechanisms underlying their individual ICP problem.

Ethical problems may arise over how aggressively therapy for intracranial hypertension should be pursued and for how long. There has always been the concern that cranial decompression or prolonged barbiturate coma may preserve patients but with unacceptably severe disability. Some patients may be salvaged from herniating with massive cerebral infarction with the use of osmotherapy but is the outcome acceptable? ${ }^{130}$ Similar 
considerations apply to some children with metabolic encephalopathies. Where such considerations have been scrutinised in patients with severe head injury, the whole spectrum of outcomes appears to be shifted so that the number of severe disabilities and persistent vegetative states are not increased. However, it is important to be sensitive to such issues based on experience of the particular cause of raised intracranial pressure in a given age group.

We are indebted to Dr J M Turner, Mr E Guazzo and Mr P Kirkpatrick for their comments on the manuscript

1 Jennett B, Teasdale G. Management of head injuries. Philadelphia: F A Davies. 1981.

2 Miller JD, Jones PA, Dearden NM, Tocher JL. Progress in the management of head injury. $B r f$ Surg 1992; 79:60-64.

3 Pickard JD, Bailey S, Sanderson H, Rees $M$, Garfield JS. Steps towards cost-benefit analysis of Garfield JS. Steps towards cost-benefit analysis
regional neurosurgical care. BMF 1990;301:629-35.

4 Minns RA. Problems of intracranial pressure in childhood. Clinics in developmental medicine 113/114. London: MacKeith Press, 1991:1-458.

5 Langfitt TW. Increased intracranial pressure. Clinical Neurosurgery 1969;16:436-71.

6 Miller JD. Normal and increased intracranial pressure. In: Miller JD, ed. Northfield's surgery of the central nervous system 2nd ed, London: Blackwell, 1987:7-57.

7 Miller JD, Dearden NM. Measurement, analysis and the management of raised intracranial pressure. In Teasdale GM, Miller JD, eds. Current neurosurgery Edinburgh: Churchchill Livingstone, 1992:119-56.

8 Saul TG, Ducker TB. Effect of intracranial pressure monitoring and aggressive treatment on mortality in
severe head injury. $\mathcal{F}$ Neurosurg 1982;56:498-503.

9 Welch K. The intracranial pressure in infants. $f$ Neurosurg 1980;52:693-9.

10 Lundberg N. Continuous recording and control of ventricular fluid pressure in neurosurgical practice. Acta Psych Neurol Scand 1960;36,Suppl 149:1-193.

11 Avezaat CJJ, von Eijndhoven JHM, Wyper DJ Cerebrospinal fluid pulse pressure and intracranial volume-pressure relationships. $\boldsymbol{f}$ Neurol Neurosurg Psychiatry 1979;42:687-700.

12 Czosnyka M, Laniewski P, Batorski L, et al. Remarks on amplitude-pressure characteristic phenomenon. In: Hoff JT, Betz AI, eds. Intracranial pressure VII Berlin: Springer Verlag 1989:255-9.

13 Obrist WD, Langfitt TW, Jaggi JL, et al. Cerebral blood flow and metabolism in comatose patients with acute head injury. Relationship to intracranial hypertension. 7 Neurosurg 1984;61:241-55.

14 Bingham RM, Procaccio F, Prior PF, Hinds CJ Cerebral electrical activity influences the effects of etomidate on cerebral perfusion pressure in traumatic coma. Brit $\mathcal{F}$ Anaes 1985;57:843-8.

15 Nordstrom CH, Messeter K, Sundbarg G, et al. Cerebral blood flow, vasoreactivity and oxygen consumption during barbiturate therapy in severe traumatic brain lesions. I Neurosurg 1988;68:424-31.

16 Rosner MJ, Becker DP. Origins and evolution of plateau waves. Experimental observations and theoretical model. F Neurosurg 1984;60:312-24.

17 Newell DW, Aaslid R, Stooss R, Reulen HJ. The relationship of blood flow velocity fluctuations to intracranial pressure B waves. $\mathcal{f}$ Neurosurg 1992;76:415-21.

18 Kirkham FJ, Levin SD, et al. Transcranial pulsed Doppler ultrasound findings in brainstem death. Doppler ultrasound findings in brainstem deat

19 Hassler W, Steinmetz H, Pirschel J. Transcranial Doppler study of intracranial circulatory arrest. $\mathscr{f}$ Neurosurg 1989;71:195-201.

20 Marmarou A, Shulman K, Larmorgese J Compartmental analysis of compliance and outflow resistance of the cerebrospinal fluid outflow system. $\mathcal{f}$ Neurosurg 1975;43:523-34.

21 Czosnyka M, Pickard JD, Whitehouse H, Piechnik S The hyperaemic response to a transient reduction in cerebral perfusion pressure-a modelling study. Acta Neurochirurgica (Wien) 1992;115:90-7.

22 Marmarou A, Maset AL, Ward JD, et al. Contribution of CSF and vascular factors to elevation of ICP in severely head-injured patients. $\mathcal{f}$ Neurosurg 1987 ; 66:883-90.

23 Czosnyka M, Harris NG, Pickard JD. $\mathrm{CO}_{2}$ cerebrovascular reactivity as a function of perfusion pressure-a modelling study. Acta Neurochirurgica 1993;121: modelling

24 Guillaume J, Janny P. Manometrie intracranienne continue. interet de la methode et premiers resultats. tinue. interet de la methode et
Revue Neurologique 1951;84:131-42.

25 Katzman R, Hussey F. A simple constant-infusion manometric test for measurement of CSF absorption. Rationale and method. Neurology 1970;20:534-44.

26 Borgesen SE, Gjerris F. The predictive value of conductance to outflow of CSF in normal pressure hydro- cephalus. Brain 1982;105:65-86

27 Czosnyka M, Batorski L, Laniewski P, Maksymowicz W, Koszewski W, Zaworski W. A computer system for the identification of the cerebrospinal compensatory model. Acta Neurochir (Wien) 1990;105:112-6.

28 Symon L, Dorsch NWC, Stephens RJ. Pressure waves in so-called low-pressure hydrocephalus. Lancet 1972; 2:1291-2.

29 Pickard JD. Teasdale GM, Matheson M, Wyper DJ, et $a l$. Intraventricular pressure waves-the best predictive test for shunting in normal pressure hydrocephalus. In: Shulman $\mathrm{K}$, et al, eds. Intracranial pressure IV. Berlin: Springer-Verlag 1980:498-500.

30 Laniewski P, Czosnyka M, Maksymowicz W. Continuous analysis of the intracranial pressure waveform as a method of autoregulatory reserve assessment. ICP VIII. Berlin: Springer Verlag (in press).

31 Miller JD, Garibi J, Pickard JD. Induced changes in cerebrospinal fluid volume. Effects during continuous monitoring of ventricular fluid pressure. Arch Neurol 1973;28:265-9.

32 Aaslid R, Markwalder T-M, Nornes H. Non-invasive transcranial Doppler ultrasound recording of flow velocity in basal cerebral arteries. $\mathcal{f}$ Neurosurg 1982;57: 769-74.

33 Newell DW, Aaslid R. Transcranial doppler. New York: Raven Press, 1992.

34 Martin JL, Perry S, Pickard JD. Cerebral blood flow and Doppler flow velocity: different responses to three vasodilators. F Cereb Blood Flow Metab 1991;11:suppl vasodila 455 .

35 Chan KH, Miller JD, Dearden NM, Andrews PJD, Midgley $S$. The effect of cerebral perfusion pressure upon changes in middle cerebral artery flow velocity and jugular venous bulb oxygen saturation after severe head injury. $\mathcal{F}$ Neurosurg 1992;77:55-61.

36 Nelson RJ, Czosnyka M, Pickard JD, Maksymowicz W, Perry S, Martin JL, Lovick AHJ. Experimental aspects of cerebrospinal hemodynamics: the relationship between blood flow velocity waveform and cerebral autoregulation. Neurosurgery 1992;31:705-10.

37 Chan KH, Dearden NM, Miller JD. The significance of posttraumatic increase in cerebral blood flow velocity: a transcranial Doppler ultrasound study. Neurosurgery 1 transcranial Do:

38 Chan KH, Dearden NM, Miller JD, Midgley S, Piper IR. Transcranial Doppler waveform differences in hyperemic and nonhyperemic patie
injury. Surg Neurol 1992;38:433-6.

39 Chan KH, Miller JD, Dearden NM. Intracranial blood flow velocity after head injury: relationship to severity of injury, time, neurological status and outcome. $\mathcal{F}$ Neurol Neurosurg Psychiatry 1992;55:787-91.

40 Schalen W, Messeter R, Nordstrom CH. Cerebra vasoreactivity and the prediction of outcome in severe traumatic brain lesions. Acta Anaesthesiol Scand 1991;35:113-22.

41 Reid A, Marchbanks RJ, Martin R, Pickard JD, Bateman N, Brightwell $R$. Mean intracranial pressure monitoring by an audiological technique-a pilot study. $\mathcal{f}$ Neurol Neurosurg Psychiatry 1989;52:610-2.

42 Campkin TV, Turner JM. Neurosurgical anaesthesia and intensive care. 2nd ed. London: Butterworth, 1986.

43 Robertson CS, Narayan RH, Gokaslan ZL, et al. Cerebral arteriovenous oxygen difference as an estimate of cerebral blood flow in comatose patients. $f$ Neurosurg 1989;70:222-30.

44 Wyatt JS, Cope M, Delpy DT, Wray S, Reynolds EOR Quantification of cerebral oxygenation and haemodynamics in sick newborn infants by near infrared spectroscopy. Lancet 1986;2:1063-6.

45 Jennett B, Teasdale G, Galbraith S, Pickard JD, et al. Severe head injuries in three countries. $f$ Neurol Neurosurg Psychiatry 1977;40:291-8.

46 Miller JD, Butterworth JF, Gudeman SK, et al. Further experience in the management of severe head injury. $\mathcal{F}$ Neurosurg 1981;54:289-99.

7 Ropper AH, O'Rourke D, Kennedy SK. Head position, intracranial pressure and compliance. Neurology 1982; :1288-91.

48 Rosner MJ, Coley IB. Cerebral perfusion pressure, ICP and head elevation. F Neurosurg 1986;65:636-41

49 Feldman Z, Kanter MJ, Robertson CS, et al. Effect of head elevation on ICP, CPP and CBF in head injured patients. F Neurosurg 1992;76:207-11.

50 Kanter MJ, Robertson CS, Sheinberg MA, et al. Changes in cerebral hemodynamics with head elevated vs head flat. In: Avezaat C, ed. Intracranial pressure VII (In press)

51 Hasan D, Vermeulen M, Wijdicks EFM, et al. Effect of fluid intake and hypertensive treatment on cerebral ischaemia after subarachnoid haemorrhage. Stroke 1989;20:1511-5.

52 Nelson RJ, Roberts J, Rubin C, Walker V, Ackery DM, Pickard JD. Association of hypovolaemia after SAH with computer tomographic scan evidence of raised
intracranial pressure. Neurosurgery 1991;29:178-82.

53 Marmarou A, Anderson RL, Ward JD, et al. Impact of ICP instability and hypotension on outcome in patients ICP instability and hypotension on outcome in patients

54 Muizelaar JP. Induced arterial hypertension in the treatment of high intracranial pressure. In: Hoff JT, Betz $\mathrm{AL}$, ed. Intracranial pressure VII. Springer-Verlag, 1989:508-10.

55 Rosner MJ, Rosner SD. Cerebral perfusion pressure management of head injury. In: Avezaat $C$, ed. 
Intracranial pressure VIII. (In press)

56 Shimoda $M$, Oda $S$, Tsugane $R$ Sato $O$. Intracranial complications of hypervolemic therapy in patients with delayed ischemic deficit attributed to vasospasm. $f$ Neurosurg 1993;78:423-9.

57 Fitch W, Pickard JD, Tamura A, Graham DI. Effects of hypotension induced with sodium nitroprusside on the cerebral circulation before, and one week after, the subarachnoid injection of blood. I Neurol Neurosurg Psychiatry 1988;51:88-93.

58 Nelson PB, Seif SM, Maroon JC, Robinson AG. Hyponatraemia in intracranial disease: perhaps not the syndrome of inappropriate secretion of antidiuretic hormone (SIADH). $\mathcal{F}$ Neurosurg 1981;55:938-41.

59 Nelson RJ, Perry S, Burns ACR, Roberts J, Pickard JD The effects of hyponatraemia and subarachnoid haemorrhage on the cerebral vasomotor responses of the rabbit. F Cereb Blood Flow Metab 1991;11:661-6.

60 Myers RE. Anoxic brain pathology and blood glucose. Neurology 1976;34:345.

61 Marie C, Bralet J. Blood glucose level and morphological brain damage following cerebral ischaemia. Cerebrovascular and Brain Metab Reviews 1991;3:29-38.

62 Reed DJ, Woodbury DM. Effect of hypertonic urea on cerebrospinal fluid pressure and brain volume. $\mathcal{F}$ Physiol (Lond) 1963;164:252-64.

63 Pappius HM, Dayes LA. Hypertonic urea-its effect on the distribution of water and electrolytes in normal and edematous brain tissue. Arch Neurol 1965;13:395-402.

64 Ravassin P, Abou-Madi M, Archer D, Chiolero R, Freeman J, Trop D, de Tribolet N. Changes in CSF pressure after mannitol in patients with and without elevated CSF pressure $f$ Neurosurg 1988;69:869-76.

65 James HE, Harbaugh RD, Marshall LF, Shapiro HM The response to multiple therapeutics in experimental vasogenic edema. In: Shulman K, Marmarou A, Mille $\mathrm{JD}$, et al, eds. ICP IV. Berlin, Springer-Verlag. 1980 $272-6$.

66 Rosenberg GA. Brain fluids and metabolism. Oxford: Oxford University Press, 1990

67 Inao S, Kuchiwaki H, Wachi A, et al. Effect of mannito on intracranial pressure-volume status and cerebra haemodynamics in brain oedema. Acta Neurochirurgica 1990; Suppl51:401-3.

68 Bell BA, Smith MA, Kean DM, et al. Brain water measured by magnetic resonance imaging: correlation with direct estimation and change following mannitol and dexamethasone. Lancet 1987;1:66-9.

69 Kaufmann AM, Cardoso ER. Delayed cerebral accumulation of mannitol in vasogenic edema. In: Avezaat C, ed. Intracranial pressure VIII. (In press)

70 Burke AM, Quest DO, Chien S, et al. The effects of mannitol on blood viscosity. F Neurosurg 1981;55 550-3.

71 Miller JD, Leech P. Effects of mannitol and steroid therapy in intracranial volume pressure relationships. $f$ Neurosurg 1975;42:274-81.

72 Muizelaar JP, Wei EP, Kontos HA, Becker DP. Mannitol causes compensatory cerebral vasoconstriction and vasodilatation in response to blood viscosity changes. $\mathcal{f}$ Neurosurg 1983;59:822-8.

73 Auer LM, Haselsberger K. Effect of intravenous mannitol on cat pial arteries and veins during normal and elevated intracranial pressure. Neurosurgery 1987; 21:142-6.

74 Harrison MJG. Influence of haemocrit in the cerebral circulation Cerebrovascular and Brain Metab Reviews circulation. Cer

75 Brown MM, Wade JPH, Marshall J. Fundamental importance of arterial oxygen content in the regulation of cerebral blood flow in man. Brain 1985;108:81-93.

76 Purves MJ. The Physiology of the cerebral circulation. Cambridge: Cambridge University Press, 1972.

77 Bruce DA, Langfitt TW, Miller JD, et al. Regional cerebral blood flow, intracranial pressure, and brain metabolism in comatose patients. $f$ Neurosurg 1973;38: 131-44.

78 Johnston IH, Harper AM. The effect of mannitol on cerebral blood flow. An experimental study. $f$ Neurosurg 1973;38:461-71.

79 Mendelow AD, Teasdale GM, Russell T, et al. Effect of mannitol on cerebral blood flow and cerebral perfusion pressure in human head injury. 7 Neurosurg 1985 ; 63:43-8.

80 Jafar JJ, Johns LM, Mullan SF. The effect of mannitol on cerebral blood flow. $\mathcal{f}$ Neurosurg 1986;64:754-9.

81 Muizelaar JP, Lutz HA, Becker DP. Effect of mannitol on ICP and $\mathrm{CBF}$ and correlation with pressure
autoregulation in severely head-injured patients. $f$ Neurosurg 1984;61:700-6.

82 Meyer FB, Anderson RE, Sundt TM, Yaksh TL Treatment of experimental focal cerebral ischaemia with mannitol. Assessment by intracellular $\mathrm{pH}$, cortical blood flow and EEG. ₹ Neurosurg 1987;66:109-15.

83 Takagi H, Saito T, Kitahara T, Morii SM, Ohwada J, Yada $\mathrm{K}$. The mechanism of the ICP reducing effect of mannitol. In: Ishii S, Nagai H, Brock

84 Smith HP, Kelly DL, McWhorter JM, et al. Comparison of mannitol regimes in patients with severe head injury undergoing ICP monitoring. $f$ Neurosurg 1986;65: undergoin. 4 .

85 Roberts PA, Pollay M, Engles C, Pendleton B, Reynolds E, Stevens FA. Effect on intracranial pressure of furosemide combined with varying doses and administration rates of mannitol. 7 Neurosurg 1987;66:440-6.

86 Smedema RJ, Gaab MR, Heissler HE. A comparison study between mannitol and glycerol therapy in reducing ICP. In: Avezaat, ed. Intracranial pressure VIII. (In press).

87 Muizelaar JP, van der Poel HG, Li Z, Kontos HA, Levasseur JE. Pial arteriolar vessel diameter and $\mathrm{CO}_{2}$ reactivity during prolonged hyperventilation in the rabbit. $\mathcal{F}$ Neurosurg 1988;69:923-7.

88 Ward JD, Choi S, Marmarou A, et al. Effect of prophylactic hyperventilation on outcome in patients with severe head injury. ICP VII. In: Hoff IT, Betz AL, eds. Berlin: Springer-Verlag, 1989:630-4.

89 Enevoldsen EM, Cold G, Jensen FT, et al. Dynamic changes in regional $\mathrm{CBF}$, intraventricular pressure,
$\mathrm{CSF} \mathrm{pH}$ and lactate levels during the acute phase of head injury. $\mathcal{F}$ Neurosurg 1976;44:191-214.

90 De Salles AAF, Kontos HA, Becker DP, et al. Prognostic significance of ventricular CSF lactic acidosis in severe head injury. F Neurosurg 1986;65:615-24.

91 Akiota T, Ota $\mathrm{K}$, Matsumato $\mathrm{A}$, et al. The effect of THAM on acute intracranial hypertension. An experimental and clinical study. In: Beks JWF, Bosch DA, Brock M, eds. Intracranial pressure III. Berlin: SpringerVerlag, 1976:219-33.

92 Gordan E, Rossanda $M$. Further studies in cerebrospinal fluid acid-base status in patients with brain lesions. Acta Anaesth Scand 1970;14:97-109.

93 Gaab MR, Seegers K, Goetz C. THAM (tromethamine, "tris-buffer"): effective therapy of traumatic brain "tris-buffer"): effective therapy of traumatic brain vil. Berlin: Springer-Verlag, 1989:616-9.

94 Wolf AL, Levi L, Marmarou A, et al. Effect of THAM upon outcome in severe head injury: a randomized prospective clinical trial. $f$ Neurosurg 1993;78:54-9.

95 Pickard JD, Mackenzie ET. Inhibition of prostaglandin synthesis and the response of baboon circulation to carbon dioxide. Nature New Biology 1973;245:187-8.

96 Edwards AD, Wyatt JS, Richardson C, et al. Effects of indomethacin on cerebral haemodynamics in very preterm infants. Lancet 1990;335:1491-5.

97 Jensen K, Öhrstrom J, Cold GE, Astrup J. The effects of indomethacin on intracranial pressure, cerebral blood flow and cerebral metabolism in patients with severe head injury and intracranial hypertension. Acta Neurochir (Wien) 1991;108:116-21.

98 Sullivan LP. Stears JC, Ringer SP. Resolution of syringomyelia and chiari malformation by ventriculosyringomyelia and chiari malformation by ventriculoatrial shunting in a patient with pseudotumour cerebri
and a lumbo-peritoneal shunt. Neurosurgery 1988;22: and a

99 Editorial. Cranial decompression. Lancet 1988;1:1204.

100 Gower DJ, Lee KS, McWhorter JM. Role of subtemporal decompression in severe closed head injury. Neurosurgery 1988;23:417-22.

101 Umezewa H, Shima K, Chigasaki H, Ishii S. Effects of the pressure gradient on hydrostatic brain edema. In: Hoff JT, Betz AL, eds. Intracranial pressure VII. Berlin: Springer-Verlag, 1989:953-6.

102 Rittierodt M, Gaab MR. Traumatic brain swelling and operative decompression: a prospective investigation. In: Avezaat C, et al, ed. Intracranial pressure VIII. In: Avezaat C, et al, ed. Intracran
Berlin: Springer-Verlag, (In press)

103 Kirkham FJ, Neville BGR. Successful management of severe intracranial hypertension by surgical decompression. Developmental Medicine Child Neurol 1986;28: 506-9.

104 Cooper PR, Moody S, Clark WK, et al. Dexamethasone and severe head injury: a prospective double blind trial. $\mathcal{f}$ Neurosurg 1979;51:307-16.

105 Saul TF, Ducker TB, Salomon M, et al. Steroids in severe head injury. A prospective randomized clinical trial. 7 Neurosurg 1981;54:596-600.

106 Braakman R, Schouten HJD, Dishoeck BMV, Minderhoud JM. Megadose steroids in severe head injury: results of a prospective double blind clinical trial. $\dot{f}$ Neurosurg 1983;58:326-30.

107 Giannotta SL, Weiss MH, Apuzzo MLJ, Martin E. High dose glucocorticoids in the management of severe head dose glucocorticoids in the management of severe head
injury. Neurosurgery 1984;15:497-501.

108 Dearden NM, Gibson JB, McDowall DG, et al. Effect of high dose dexamethasone on outcome from severe high dose dexamethasone on outcom
head injury. $\mathcal{I}$ Neurosurg $1986 ; 64: 81-8$.

109 Floyd RA, Carney JM. Protection against oxidative damage to CNS by $\alpha$-Phenyl-tert-butyl Nitrone and other spin-trapping agents: a novel series of nonlipid free radical scavengers. In: Marangos PJ, Lal $\mathrm{H}$, eds. Emerging strategies in neuroprotection, Boston: Birkãuser, 1992:252-72.

110 Halliwell B, Gutteridge JMC. Free radicals in biology and medicine. Oxford: Clarendon Press, 1985.

111 Hall ED. Lazaroids: novel cerebroprotective antioxidants. In: Marangos PJ, Lal H. Emerging strategies in neuroprotection. Boston: Birkãuser, 1992:224-37.

112 Muizelaar JP, Marmarmou A, Young HA, et al. Improving the outcome of severe head injury with the oxygen radical scavenger polyethylene glycol-conjugated superoxide dismutase: a Phase II trial. $f$ gated superoxide dismut

113 Welsh FA, Sims RE, Harris VA. Mild hypothermia prevents ischemic injury in gerbil hippocampus. $\mathcal{f}$ Cereb

114 Schwartz M, Tator CH, Rowed DW, et al. The 
University of Toronto Head Injury Treatment Study: a prospective randomized comparison of pentobarbitat and mannitol. Canad $\mathcal{Y}$ Neurol Sci 1984;11:434-40.

115 Ward JD, Becker DP, Miller JD, et al. Failure of prophylactic barbiturate coma in the treatment of severe head injury. $\mathcal{F}$ Neurosurg 1985;62:383-8.

116 Eisenberg HM, Frankowski RF, Condant CG, et al. High dose barbiturate control of elevated intracranial pressure in patients with severe head injury. $\mathcal{f}$ Neurosurg 1988;69:15-23.

117 Batjer HH. Cerebral protective effects of Etomidate: experimental and clinical aspects. Cerebrovasc Brain Metab Rev 1993;5:17-32.

118 Leggate JRS, Dearden NM, Miller JD. The effects of gammahydroxybutyrate and thiopentone on ICP in gammahydroxybutyrate and thiopentone on ICP in severe head injury. In: Miller JD, Teasdale GM, et al
eds. Intracranial pressure VI. Berlin: Springer-Verlag, 1986:754-9.

119 Murphy PG, Myers DS, Davies MJ, et al. The antioxidant potential of propafol (2,6-diisopropylphenol). Brit $\mathfrak{f}$ Anaes 1992;68:613-8.

120 Bedford RF, Persing JA, Pobereskin L, Butler A. Lidocaine or thiopental for rapid control of intracranial hypertension? Anaesth Analg 1980;59:435-7.

121 Meldrum B. Protection against ischaemic neuronal damage by drugs acting on excitatory neurotransmission.

122 Choi DW. Methods of antagonizing glutamate neurotoxicity. Cerebrovasc Brain Metab Rev 1990;2:105-47.

123. Inglis FM, Kuroda Y, Bullock R. Glucose hypermeta- bolism after acute subdural haematoma is ameliorated by a competitive NMDA antagonist. $\mathcal{f}$ Neurotrauma 1992;9:75-84.

124 Gill R, Foster AC, Woodruff GN. MK801 is neuroprotective in gerbils when administered during the postischaemic period. Neuroscience 1988;25:847-56.

125 Park CK, Nehls DG, Graham DI, Teasdale GM, McCulloch J. The glutamate antagonist MK801 reduces focal ischaemic brain damage in the rat. $A n n$ Neurol 1988;24:543-55.

126 Izumi Y, Roussel S, Pinard E, Seylaz J. Reduction of infarct volume by magnesium after middle cerebral artery occlusion in rats. $₹$ Cereb Blood Flow Metab 1991;11:1025-30.

127 Levene M. Neonatal neurology. Edinburgh, Churchill Livingstone. 1987.

128 Bruce DA, Alavi A, Bilaniuk, et al. Diffuse cerebral swelling following head injuries in children: the syndrome of "malignant brain edema". $\boldsymbol{f}$ Neurosurg $1981 ; 54: 170-8$.

129 Aldrich EF, Eisenberg HM, Saydjari C, et al. Diffuse brain swelling in severely head-injured children. $\mathcal{F}$ Neurosurg 1992;76:450-4.

130 Harrison MJG. Is shrinking the brain a good thing after cerebral infarction? In: Warlow C, Garfield J, eds. Dilemmas in the management of the neurological patient. Edinburgh: Churchill Livingstone, 1984:62-73.

131 Pullen RGL, De Pasquale M, Cserr HF. Bulk flow of cerebrospinal fluid into brain in response to acute hyperosmolality. Amer $\mathcal{F}$ Physiol 1987;253:538-45. 